\title{
Creating Capacity Through Health Education: What We Know and What We Don't
}

\author{
Noreen M. Clark, PhD \\ Kenneth R. McLeroy, PhD
}

\begin{abstract}
Researchers in health education have rarely convened to outline research priorities in the field. This article discusses the results of a meeting to develop a research agenda aimed at creating capacity to promote and maintain health. Salient research findings related to individual and community health are summarized and priority issues for future research are presented.
\end{abstract}

\section{AN ERA OF CHANGE}

Few would deny that the quality of research in health education has risen significantly in the past two decades. One might speculate about why this is the case. A reason may be that in both the profession and in academic training institutions there has been recognition that the social and behavioral sciences constitute the scientific basis for health education practice. This may seem obvious to observers in the 1990s, but in years past there was some resistance among health educators to acknowledge the social and behavioral sciences as the theoretical foundations of practice, and social and behavioral scientists doubted whether they should be interested in applications of their concepts in health education programs. The resistance has melted away and the inherent connection between theory and practice gets stronger all the time.

Another reason may be that, in recent years, there has been widespread and increased recognition across society of the importance of psychosocial and behavioral factors in health status. Preventing illness has to do with how people behave (maybe as much as $50 \%$ according to the Institute of Medicine) and with their social as well as physical environment, and this realization has been accompanied with the idea that educational efforts to change policy and behavior —of individuals, communities, and organizationscurrently constitute our best chance of promoting health.

Further, the need to promote health and achieve control over medical care costs has stimulated funding agencies to increase their support for evaluation of health promotion and education interventions. Often these funders have had expectations that, quite frankly, have improved the nature of the research conducted. For example, peer reviews conducted

Noreen M. Clark is a professor in and the chair of the Department of Health Behavior and Health Education, School of Public Health, University of Michigan. Kenneth R. McLeroy is a professor in and the chair of the Department of Health Promotion Sciences, College of Public Health, University of Oklahoma.

Address reprint requests to Noreen M. Clark, $\mathrm{PhD}$, Department of Health Behavior and Health Education, School of Public Health, University of Michigan, 1420 Washington Heights, Ann Arbor, MI 48109-2029; phone: (313) 764-9494; fax: (313) 763-7379. 
through funding agencies have certainly played a role in creating the expectation that health education be theory based, multidisciplinary, and outcome oriented.

Obviously, we are much farther from the mark in terms of the sophistication of our research and the resources available to support that research than most of us would wish. Nonetheless, there have been remarkable strides in the past years; achievements of which we can all be proud (see, e.g., Freudenberg et al., ${ }^{1}$ Steckler et al., ${ }^{2}$ Mullen et al., ${ }^{3}$ Marin et al., ${ }^{4}$ and Israel et al. ${ }^{5}$.

\section{Revisiting Old Venues and Finding New Directions}

Recent accomplishments notwithstanding, we are on the threshold of knowledge about individual and collective health behavior, protective social environments, and interventions to improve all of these. This article intends to raise some general issues, points we might consider as we rethink our current approaches to health education research and pioneer new ones. This article will briefly raise issues that are discussed more fully in the five articles that follow: theory, settings, strategies, evaluation, and special populations in health education research.

\section{HEALTH EDUCATION THEORY}

\section{Distinguishing Theories of Behavior From Conceptual Models for Practice}

As Freudenberg et al. ${ }^{1}$ demonstrate in this issue, the past two decades have been rich in theoretical and empirical work. We have at our disposal a range of excellent theoretical constructs to guide research and practice. But there is some confusion in the way the word theory is used by health education researchers and practitioners. Clearly, to push a field of endeavor forward there must be a common language. In fact, an important contribution to our progress in health education was the development almost 20 years ago of a taxonomy of health education terms, which was updated and published annually for several years before the activity was discontinued. ${ }^{6}$ Our shared health education language, while more precise than in years past, is not yet precise enough. An area of haziness is the language we use in discussing theory. We tend to mix together constructs that probably ought to be distinguished. For sake of discussion, we will categorize theories according to their intention and utility in the following manner: 1 . theories of behavior; 2 . conceptual frameworks for practice; and 3. theoretical principles.

Category 1 theories attempt to predict or explain why people behave as they do in relation to their health. These may be theories that focus primarily on psychological factors such as the health belief model, ${ }^{7}$ health locus of control, ${ }^{8}$ attribution theory, ${ }^{9}$ the theory of reasoned action, ${ }^{10}$ and the transtheoretical model of behavior change (stages of

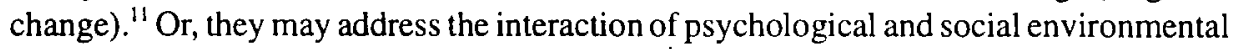
factors such as social cognitive theory, ${ }^{12}$ self-regulation, ${ }^{13}$ Freire's psychosocial model, ${ }^{14}$ and theories of social support and social networks. ${ }^{15}$

We also have important conceptual frameworks for practice (Category 2 theories); that is, theories that describe the conditions under which health education interventions can be made to be effective and efficacious. These theories include, for example, PRECEDE/PROCEED, ${ }^{16}$ PATCH, ${ }^{17}$ the social ecological model,,${ }^{18,19,20}$ and the growing body of work on empowerment. ${ }^{21,22}$ There are also a number of theoretical principles 
(Category 3 theories) that have evolved from behavioral theories and conceptual frameworks for practice and have been associated with evidence that health status and/or behavior change has occurred. These include, for example, the principle of tailoring advice and health messages, ${ }^{23}$ contracting, ${ }^{24}$ and various communication techniques. ${ }^{25,26}$

A point raised by Freudenberg et al. ${ }^{1}$ is that we have lots of (Category 1) theories of behavior but limited empirical evidence about how they work in whole and/or part. That is not to say that these theories have not received or are currently garnering a fair amount of attention in health education research. Yet we are still at a rudimentary stage of understanding (1) how they actually function to produce results, (2) if some are better than others in producing outcomes, (3) which components or critical mass of constituent concepts or principles are needed to achieve change, and (4) which are more or less relevant to different problems and populations of potential leamers.

We are not very clever regarding how to measure constructs from these theories. There are only a few cases, for example, health locus of control ${ }^{8}$ and the transtheoretical model of behavioral change," where significant effort has gone into developing measures sensitive to change and applicable to a variety of health problems. But even in cases where this type of effort has been expended, constructs and scales have not been widely or diversely validated.

There is the related though somewhat different problem of how to adequately apply theoretical constructs in an intervention so that effects may be tested. Some Category 1 theories are easier to apply than others. Some, for example social cognitive theory, ${ }^{12}$ aim to explain how health behavior comes about. Designing interventions based on these explanations is somewhat evident. However, other theories, for example the health belief model,' aim only to predict behavior and provide very little to indicate how the factors influencing behavior can be manipulated. The knowledge that people are more likely to use medicine when they believe the consequences of their illness to be serious does not inherently explain how to make them believe in the seriousness of the illness. Because translation of theory to "real life" is not always easy, interventions have not always comprised strong applications. They have also tended to be eclectic, drawing bits and pieces from a variety of available constructs; that is, they are not purely one theory or another. Perhaps as a result we have not progressed as much as we might wish in identifying how Category 1 theories work, and of these, which are most robust and valuable in achieving change.

Assessing the contribution of Category 2 theories-conceptual frameworks for practice-poses additional problems. One is that these frameworks combine not only what we know about human behavior and influences in the social environment but also what we wish the ideal situation to be. Practice in a democratic society reflects what we value. Empowerment theories, ${ }^{21,22}$ for example, are based on the belief that equality and equity of participation are related not only to access to needed health services and physical health status but to mental and emotional health as well. Perhaps the most widely used practice model is PRECEDE/PROCEED,${ }^{16}$ and one reason may be that it values efficient as well as effective use of resources, a tenet important in equitable delivery of public health services. The point is that practice models do not purport to explain or predict behavior as Category 1 theories do. Rather, they describe the individual, organizational, and community-wide conditions and processes that should be fostered to bring about change.

Another dilemma in determining the relative value of different conceptual frameworks for practice rests in the fact that they are so comprehensive. They often try to account for the potential learner and range of factors influencing his or her health behavior; the health 
educator and the diverse influences on his or her professional and personal performance; the participating organizations and the spectrum of organizational factors enabling and detracting from the implementation of the health education program; the norms, beliefs, cultural patterns, and economic factors evident in the community where the education takes place; and so on.

These characteristics of Category 2 theories give rise to several questions: (1) How does one ascertain that the model has been adequately applied? (2) Can models of practice be tested in the same way we test theories of behavior? (3) Do all the wide-ranging elements need to be in place for the model to receive a fair evaluation? (4) How are changes attributable to a given practice model to be separated from those attributable to the behavioral theories also employed? and (5) What are the appropriate outcomes for assessing conceptual frameworks for practice? They appear to differ from those appropriate for behavioral theories. For example, is a reasonable test of the social ecological model institutionalization of a program regardless of whether or not the health behavior of the program target audience changed?

To make matters more complex, both behavioral theories and conceptual frameworks for practice give rise to Category 3 theories, that is, theoretical principles. The fact is, some approaches to behavior change and professional practice are known to achieve certain ends. If individuals have influence in decision making, they appear to be more satisfied with the decision. ${ }^{27}$ If learners make public their intention to change, for example, to follow a low-fat diet, they are more likely to do so. ${ }^{24}$ But these principles, as important as they may be, provide only a glimpse at the pictures of behavior change and professional practice. They may be important, even necessary, in interventions but they do not appear to be sufficient to describe the mechanisms of change related to complex health problems. And, as is true with the other two categories of theory, the extent to which they produce extensive or long-lasting results or prove effective with diverse populations has not been demonstrated.

The richness in the range of theories available for designing and evaluating health education interventions gives rise to difficult questions and dilemmas. As Freudenberg et al.' make clear, we have much to work with but there is much work to be done.

\section{INTERVENTION STRATEGIES}

Steckler and colleagues ${ }^{2}$ posit that health problems and interventions to address them must be conceived comprehensively. That is, we must identify those aspects of a problem that are manifest in individual behavior, in the social and physical environment of the community, and in the policies regulating both. They note that interventions aimed at any one of these three levels (individual, community, policy) will affect and be affected by the others. They also discuss the role of mass media, which appear to exert a powerful influence across the three levels and about which we know little.

\section{Individual Behavior}

Most health education research has been directed toward individual behavior. In the past 15 years, a large number of studies has provided evidence that health education can contribute to changes in behavior and improved health status. Findings from well-designed studies have demonstrated, for example, that preoperative instruction can 
influence recovery, ${ }^{28}$ and that education engenders improved compliance, ${ }^{29}$ disease self-management, ${ }^{317}$ patient-provider communication,${ }^{31}$ use of health services, ${ }^{32}$ symptom profiles and functioning in chronic disease, ${ }^{32.33}$ diet,,${ }^{34}$ exercise level, ${ }^{35}$ and intentions not to smoke. ${ }^{36}$

Several generalizations can be made about the work regarding individual behavior undertaken to date. One is that most successful strategies have been derived from theories of behavior, a fact also noted by Freudenberg et al. ${ }^{1}$ Another is that when viewed generally (i.e., all interventions related to a given health problem vs. only those meeting some criteria of quality), changes in knowledge exceed changes in behavior. ${ }^{37,38}$ Still another, noted also by Freudenberg et al.,' is that intervention strategies have been eclectic, employing a range of techniques and theoretical principles. ${ }^{39}$

At least two needs are evident given these observations. First, we need to use criteria for quality in designing interventions. We need to assess existing work to determine the theoretical approaches and principles that have yielded empirical results, consider them a minimum standard, and test them further. One application is not enough to prove a strategy's worth. Second, we need sustained work related to a given health problem. Conducting only a few studies in any one area (e.g., physical functioning, arthritis, diet) is insufficient to determine the effectiveness of a health education model.

\section{Community-Level Interventions}

Steckler et al. ${ }^{2}$ argue that approaches focused on individual behavior leave out important influences in the social cultural environment. To have enduring effects, interventions must have an impact on social norms and accepted ways of functioning that may be deleterious to health. Further, this influence must be of a type that is acceptable to communities of people, that is, consistent with their values and their definitions of health and quality of life. Several community-focused strategies have been examined in the past decade that attempt to connect health professionals to communities, provide access to services, and develop community capacity to recognize and resolve health problems. Successful strategies have involved social networks ${ }^{40}$ and lay health advisers, natural helpers in a community who have the stature and ability to reach others. ${ }^{41,42}$ Forming coalitions of key community groups and organizations has also been shown to increase people's participation in health programs ${ }^{43}$ and mobilize community residents to take specific actions related to health. ${ }^{44}$

Strategies to imbue community residents with a sense of efficacy and capacity, often referred to as empowerment strategies, have been shown to contribute to changes in health outcome, for example, improved birth outcomes for homeless women, ${ }^{45}$ in government health policy, ${ }^{46}$ and in public awareness (e.g., the consequences of excess drinking). ${ }^{47}$

Few rigorous studies of interventions focused on community-wide change are available. Yet this seems a very promising area of work. The research design and measurement issues are significant in this form of research, and, as noted by Israel et al., ${ }^{5}$ in some ways our methods are not yet a match for the complexity of the interventions. Further, community-wide interventions often aim at intermediate outcomes, say forming coalitions or increasing a sense of empowerment, and the link from these to improvements in health have not been examined. The potential for community-targeted approaches to reach large numbers of people, especially populations that have been underserved, makes them very appealing and worthy of much more attention than they currently receive. 


\section{Policy-Level Interventions}

Policy interventions as discussed by Steckler et al. ${ }^{2}$ refer to efforts to bring about new laws or administrative regulations that intend to change the physical or social environment to be more protective of health. Interventions have been shown to be successful in generating policies to protect worksites from toxins, ${ }^{48}$ eliminating toxic substance transport through neighborhoods, ${ }^{49}$ and designating smoke-free public places, ${ }^{50}$ to name a few.

Steckler et al. ${ }^{2}$ suggest that interventions to engender policy change may be among the most compelling because the possibilities for influencing the behavior of large numbers of people are great. To date we have few evaluation precedents to guide our work. The evaluation problems are tricky ones to soive. Ideally, assessment would demonstrate that the intervention strategy produced the policy change, the policy change produced the desired behavior, and the behavior contributed to the health outcome. Making these connections clear may be impossible. The challenge may be to identify indicators that most would accept as reliable and valid signs that change is occurring in the desired direction. Difficulties notwithstanding, the potential payoff associated with policy-directed interventions likely offsets the costs of learning how to assess their success.

\section{Mass Communications}

Conventional wisdom and very few studies tell us that mass media can create awareness of health problems, ${ }^{51}$ influence perceptions about health, ${ }^{52}$ and even change health behavior (see, e.g., Montgomery's 1993 report on designated drivers ${ }^{53}$ ). Steckler et al. $^{2}$ believe the media exert significant influence on individual behavior, community environments, and development of policy. They note three forms of media-related interventions that deserve study: public health campaigns; media advocacy, that is, influencing media to examine a given health-related problem; and enter-education, that is, promoting healthful practices by inserting information and role models into media entertainment formats (television, video games, and the like). Undertaking evaluation of these forms of intervention requires new research designs, methods, and measures. But, they conclude, given the boom in media-related technology and informatics, the potential for such strategies to shape health behavior and influence health status could increase exponentially in the next two decades.

\section{SETTINGS FOR HEALTH EDUCATION}

Mullen and colleagues ${ }^{3}$ make the point that settings where health education is implemented are channels for reaching defined populations. The settings most often selected for health education interventions-schools, worksites, and medical care facilities-also offer the potential for institutionalizing effective interventions through their organizational policies and resource allocations. For example, some well-known health education interventions to reduce cardiovascular risk behavior have used entire communities as settings. Some have enjoyed a degree of success, ${ }^{54}$ others have not. ${ }^{55}$ But far and away the greatest number of rigorously evaluated health education interventions for changing individual behavior have been conducted in specific institutional settings. 
As we move into an era more oriented toward prevention of disease, we will likely seek to intervene earlier and earlier in the lifespan to obviate, as soon as possible, diseases that are costly in both human and economic terms. Reaching children will become even more important, and schools will become a more significant venue. Mullen et al. ${ }^{3}$ point out that there are strong precedents for work in this area.

School health education curricula for middle-school children have influenced their knowledge, attitudes, and behavior regarding risk reduction, ${ }^{56}$ although not all programs can claim success. ${ }^{57}$ Secondary school students participating in health education curricula have decreased their alcohol, tobacco, and drug use, but not seat belt use behavior. ${ }^{57}$ They have improved their diets ${ }^{58}$ and delayed sexual activity or used a condom when engaging in sex. ${ }^{59}$ Many children in the United States have chronic disease; at least one study suggests that self-management education provided at the school site can improve the health status and school performance of children with asthma. ${ }^{60}$

But many questions remain. What are the behaviors best addressed in school programs? Is the best way to intervene through traditional curricular approaches? What are the appropriate interventions for particular age groups? How much education is needed to sustain change over time and have an effect in adulthood? Mullen et al. ${ }^{3}$ suggest that the potential for school as the setting for health education has not yet been adequately explored.

\section{Worksite}

Reaching the population through worksite programs has tremendous appeal because most U.S. citizens of working age are employed. Work-based programs directed toward cardiovascular risk reduction, diet, back injury, and arthritis self-management have shown small but significant effects on participants' behavior. ${ }^{61}$ They have also been shown to generate savings equivalent to their costs. However, many questions need to be addressed if we intend to maximize the potential for work-based programs. Between one-fourth and half of those given the opportunity actually participate. ${ }^{62}$ What groups are best reached at work? What are alternative ways to reach them? How can education be integrated to be more seamless in the work day? What policies and aspects of the social environment influence behavior change? Which programs are simultaneously most effective and most affordable?

\section{Health Care Settings}

It is in the medical care setting that the bulk of rigorously evaluated health education intervention studies have been carried out in the United States. Most have concerned chronic disease and have been mounted in concert with or assuming the existence of clinical services. Health education related to medical service indeed may become a growth industry as the U.S. health care system develops a prevention focus. In terms of clinical outcome, quality of care, and patient satisfaction, health education is being closely scrutinized by managed care, health maintenance, and other organizations redrawing the services picture. There is evidence to suggest the scrutiny is warranted and these interventions make a difference. Changed patient behavior and/or health status has been associated with programs provided in conjunction with clinical services for asthma, ${ }^{63}$ arthritis, ${ }^{64}$ coronary artery disease, ${ }^{65}$ and diabetes ${ }^{66}$ Positive change related to nonchronic 
conditions has also been documented, for example, reduced pain ${ }^{67}$ and improved pregnancy outcomes. Computer-based interventions to further clinical goals have shown promise, for example, to decrease smoking ${ }^{68}$ and to motivate women to seek mammography. ${ }^{69}$

Still, many questions remain. What elements of an intervention must be in place to achieve quality of life and clinical goals related to specific diseases? Which approaches for which conditions are linked to outcomes? How can problems be overcome related to time and cost of programs and ability of health care professionals to successfully educate their patients? Training professionals is a promising route to reaching more patients and influencing their behavior, ${ }^{70}$ but to date few programs ${ }^{71}$ have demonstrated change for patients as a result of training health professionals. The existing work in health care settings provides a strong basis for future research. The population with chronic disease is increasing, and the need to achieve clinical and other outcomes related to patient functioning is increasingly critical. Research related to interventions in health care settings continues to be a compelling line of inquiry.

Mullen et al.$^{3}$ make an important observation about the next level of research across these settings for health education. We have achieved successes, yet these have not been widely replicated. How can model programs best be disseminated? We have some good examples of program dissemination (the $\mathrm{CATCH}$ project in schools $\mathrm{s}^{72}$ and the Texas experience in worksites ${ }^{73}$ ). What can we learn from these examples?

\section{WORKING WITH UNDERSERVED POPULATIONS}

Marin et al. ${ }^{4}$ have looked at issues in conducting research with special population groups, groups of similar culture, gender, and age. They have noted that the official classifications we employ (African American, Hispanic/Latino, Asian American, Native American), and the less official terms we use (e.g., elderly, adolescent) to describe these populations often have very little meaning either to researchers or to the people so labeled. We have had the tendency to view groups of people that share some characteristic (e.g., race, language, country of origin) as being of the same culture. This is far from accurate. The cultures represented within any broad category of people (e.g., Asian Americans, elderly) are very diverse.

The long-standing idea that there is an "average person" in the United States has been influenced by existing data that do not account for large and growing segments of our population. Marin et al. ${ }^{4}$ observe that interventions based on these data and developed for general audiences of "average Americans" are probably much less effective than those that take into account the culture, social norms, and traditional practices of subgroups of the population. While some data exist to support this observation, ${ }^{74.75,76}$ Marin et al. ${ }^{4}$ make clear that we need more comparative research to demonstrate what we all suspect to be the case: group-specific programs are more effective. But further, we need to understand how and why they are more effective.

Research evaluating the relative advantages of interventions designed for diverse groups is very limited, but data describing psychosocial factors and health practices clearly indicate group differences. For example, recent work in HIV/AIDS prevention has illustrated significant cultural differences in condom use. ${ }^{77.78}$ Motives for smoking and using alcohol appear to differ by ethnic group ${ }^{79,80}$ Self-management of disease seems to differ, ${ }^{81}$ as does blood pressure control, ${ }^{82}$ diet and exercise, ${ }^{83}$ and so on. But we do not know what gives rise to these differences and what kinds of interventions best account for them. 
Preliminary evaluative work suggests that some learning approaches may be better than others in reaching diverse, underserved populations. Some have also been linked to changed health behavior or health status. Peer counseling, for example, has been shown to be effective with older adults with arthritis, ${ }^{84}$ with African American women at risk of AIDS,${ }^{77}$ and in smoking cessation with Latino groups. ${ }^{74}$ Focusing on family members as educators and caregivers appears to produce results in populations of older adults with debilitating diseases ${ }^{85}$ and among groups of Native Americans. ${ }^{86}$ Self-help groups, church leaders as educators, training of lay health advisers; all these approaches seem to hold promise. ${ }^{42.74,87,88}$

Marin et al. ${ }^{4}$ make the point that ways such as these for working in diverse cultures have to be empirically derived and may even require new theories of behavior. We need data that describe how culturally relevant and appropriate approaches work, and data that illustrate the relative benefits of taking one approach rather than another. We have to be much more creative in designing interventions to build on traditional practices and cultural norms. And, borrowing a theme from Israel et al., ${ }^{5}$ we have to use evaluative methods that ensure a fair test of these new approaches. Part of the evaluative process includes coming to understand how different groups of people define functioning, quality of life and health, and taking measurements accordingly. ${ }^{89}$ The impact and outcome measures we conventionally use to assess interventions may need to be adapted or replaced in light of people's diverse expectations and values. The extent to which interventions are able to prevent disease or reduce the disability, disruption, and cost that disease generates in the society as a whole may be directly related to how closely they address the unique experience of diverse subgroups of the population.

\section{EVALUATION}

\section{Quantitative and Qualitative Approaches}

Israel et al. ${ }^{5}$ have tackled the problem of evaluation of health education: what is needed so that our evaluation designs, methods, and measures are employed most effectively in pursuit of public health. They acknowledge that the social and behavioral sciences have borrowed heavily from the physical sciences, employing, primarily, experimental research designs and quantitative methods. Quasi-experimental evaluation designs ${ }^{32,90-96}$ have been developed in the attempt to achieve a comparable level of laboratory control in the natural settings where most health education researchers work. These designs and methods are an effort to account for all the influences that might produce a result instead of, or in addition to, the health education intervention. They are considered the most credible precisely because they have been successfully used in biomedical research. However, in the transition from that venue to social behavioral research, the designs may have lost some of their robustness, given the number of uncontrollable factors at play in virtually all contexts in which health education is delivered. Few provide all the information that we need when evaluating interventions that are essentially social, psychological, and behavioral in their construction and intention.

Israel et al. ${ }^{5}$ make the point that although collecting quantitative data gives us an idea of the dimension of effects and enables us to identify salient relationships among and between variables of interest, these data may oversimplify complex facets of a problem and fail to convey fully the richness and texture of human experience. They note that collection and analyses of qualitative data to complement quantitative approaches to 
health education evaluation are becoming not only accepted but popular. ${ }^{97-100}$ In being "qualitative," researchers have borrowed from work in anthropology and other fields where ethnographic methods are used to describe the subtleties and nuances of culture. Israel et al. ${ }^{5}$ also call for development of ways to more effectively bring together both approaches. They observe that for some, the terms quantitative and qualitative suggest that evaluation is a bifurcated process rather than different elements of the same process. Ideally, most evaluations would include sufficient quantitative data to assess the reach and generalizability of an intervention, and qualitative data to determine the depth and significance of change for individuals and communities (including unintended effects, if any).

What is the right balance or mix of methods to provide the richest evaluative picture? What designs and methods are most appropriate for particular problems and populations? The heterogeneity of society and the complexity of health problems and solutions likely demand a variety of approaches to evaluation. No one way applies to all situations. To date we have had the most confidence in quantitative, cxperimental approaches. We need to develop ways to make these approaches better fit the type of problems we are studying. We also need to explore the potential for qualitative approaches; determine how they round out or change the evaluative picture. We need to recognize and employ existing valid and reliable qualitative methods and develop new methods that will generate as much confidence as those in conventional quantitative studies. We need to discover how the two ways of thinking about evaluation can be integrated most successfully in assessments of health education interventions. This integration, of course, would include enhanced use of statistical analyses.

\section{Process and Outcome}

When one peruses the literature related to a wide variety of health education interventions delivered to many different types of populations and concerning many different types of health problems, an interesting tendency emerges. Articles are likely to fall into two categories. First are those in which the health education evaluation is described in detail, and findings are presented and discussed. In this type of article, there is little if any description of an intervention and the theoretical principles that guided its development. The second type of article is essentially a description of an intervention in detail. In this type, there is virtually no presentation of findings. Sometimes there is a reference to another article where evaluation results are provided, but usually not.

The net effect is that it is often difficult to determine the nature of health education interventions that have produced outcomes. There may be explanations for this apparent gap in our understanding of the processes of education and the results they produce. For example, researchers who believe in the worth of health education programs may pay more attention to the evaluation of program outcomes and communication of results than the provision of in-depth descriptions of the program interventions. On the other hand, when program outcomes are less clear, researchers may focus their attention on the publication of project descriptions rather than the publication of data on program outcomes.

Israel et al. ${ }^{5}$ pick up on another facet of the process/outcome problem also alluded to by Freudenberg et al. ${ }^{1}$ In aiming for effect in our interventions, we have mounted programs that draw on a spectrum of theoretical approaches. Conventional wisdom and minimal data suggest that more is better in health education. So we put together programs 
that meld constructs from a variety of theories and models and are severely constrained in the way we can evaluate them. To mount multifactorial research designs generally requires distinct program components and very large populations, not to mention a sizable budget. To an extent, we are still at the stage of "black box" research in health education.

Of course our presentation of each of the above observations is oversimplified, but each is also partially correct and contributes to our understanding of the schism between process and outcome. We know some things, but certainly not enough about the nature of effective health education interventions.

What will help to close the gap? Some things are apparent; for example, developing distinct and powerful program components (built on sound theoretical constructs) and mounting multifactorial research designs. Israel et al. ${ }^{5}$ also discuss the importance of process evaluation ${ }^{101,1122,103}$ as a way to generate additional evaluative information, especially to determine if complex interventions were implemented as intended and how elements functioned.

\section{Summarizing Health Education Data}

There is another way to think about the gap between process and outcome that deserves the attention of health education researchers. With some exceptions, ${ }^{104,105}$ we have not employed methods of analyses of health education intervention results across studies. Although there are fewer articles than we would wish in the literature that adequately describe both program components and evaluation results, they do exist, and these might lend themselves to analyses that help us to see where we are or are not making progress. It is important to know, for example, what outcomes have been achieved if one looks across programs focused on a given health problem: heart disease risk reduction, diabetes self-management, and so on. But it is also important to determine the constellation of theoretical constructs that are most likely to produce results. For example, what elements of self-regulation, social support, or empowerment are related to change and what kinds of change? We need to employ meta-analyses and other analytical techniques across existing studies to summarize what we know.

\section{The Link Between Program Impact and Outcomes, and the Persistence of Both}

Israel et al. ${ }^{5}$ raise another salient issue. We expect health education interventions to produce changes in behavior (the impact) and changes in health status, or quality of life, or use of health services, and so on (the outcome). For example, if people learn in an asthma self-management program to deal with their disease more effectively, we expect that they will have fewer wheezing episodes, experience less disruption in their lives, and use the emergency department less often. To date, evaluations have tended to document either impact or outcome. There has been some (see Steckler et al. ${ }^{2}$ ), but significantly little, work demonstrating the link between the two; for example, showing how specific changes in behavior generate specific changes in health status. There is reason to be cautious in claiming that health education interventions will produce certain outcomes (e.g., less health care use). The number of factors influencing the use of health services is great and many are not within the scope of a single health education program. Indeed, many health education programs aim only to reach intermediate outcomes (impact), those 
factors that are hypothesized to influence health status, or some other outcome. In some situations, of course, the ultimate desired outcome may well be achievable. It seems logical, and has been well argued, ${ }^{16,106}$ that to be considered successful, health education interventions, given that they arise from social and behavioral theory, must produce changes in behavior, and failure to have such an impact is less forgivable than failure to reach a health status or related outcome. All these points notwithstanding, we have not explored in very many cases the relationship between impact and outcome, and this is an important area for work.

Similarly, we have in very few cases assessed the persistence of impact or outcome over time. An evaluation that covers more than 2 years is an exception. Only if we can mount programs and trace effects over longer periods will we come to understand not only the longevity of results but the pattern of interventions that can help to sustain change. It seems crucial to know if the link between impact and outcome not only exists but persists. If a program develops the ability to use refusal skills, and using them is associated with lower rates of smoking among children, do children continue to employ these skills into adolescence and does refusing continue to relate to abstinence? If a program enables people to act in an empowered way, and this is associated with greater access to preventive health services at one point in time, is the link between the behavior and outcome evident 5 years or a decade later? And finally, what research designs, data collection methods, and forms of data analyses are most reliable and valid in detecting relationships and measuring change over time?

The health education research agenda for the next decade is full of challenge and opportunity. The articles in this issue provide a guide to priorities and promising directions we might take.

\section{References}

1. Freudenberg N, Eng E, Flay B, Parcel G, Rogers T, Wallerstein N: Strengthening individual and community capacity to prevent disease and promote health: In search of relevant theories and principles. Health Educ Q 22(3):290-306, 1995.

2. Steckler A, Allegrante JP, Altman D, Brown R, Burdine JN, Goodman RM, Jorgensen C: Health education intervention strategies: Recommendations for future research. Health Educ $Q 22(3): 307$ 329, 1995.

3. Mullen PD, Evans D, Forster J, Gottlieb NH, Kreuter M, Moon R, O'Rourke T, Strecher VJ: Settings as an important dimension in health education/promotion policy, programs, and research. Health Educ Q 22(3):330-347, 1995.

4. Marin G, Burhansstipanov L, Connell CM, Gielen AC, Helitzer-Allen D, Lorig K, Morisky $\mathrm{DE}$, Tenney $\mathrm{M}$, Thomas S: A research agenda for health education among underserved populations. Health Educ $Q$ 22(3):348-365, 1995.

5. Israel BA, Cummings KM, Dignan MB, Heaney CA, Perales DP, Simons-Morton BG, Zimmerman MA: Evaluation of health education programs: Current assessment and future directions. Health Educ Q 22(3):366-391, 1995.

6. Health Education Information Retrieval System, Johns Hopkins University, 1978.

7. Janz NK, Becker MH: The heal th belief model: A decade later. Health Educ Q 11:1-47, 1984.

8. Wallston KA, Wallston BS: Locus of control and health. Health Educ Monographs 6:107-117, 1978.

9. Lewis FM, Daltroy LH: How causal explanations influence health behavior: Attribution theory, in Glanz K, Lewis FM, Rimer BK (eds.): Health Behavior and Health Education: Theory, Research and Practice. San Francisco, CA, Jossey-Bass, 1990, pp. 92-114. 
10. Ajzen I, Fishbein M: Understanding Attitudes and Predicting Social Behavior. Englewood Cliffs, NJ, Prentice Hall, 1980.

11. Prochaska JO, DiClemente CC: Towards a comprehensive model of change, in Miller WR, Heather N (eds.): Treating Addictive Behavior. New York, Plenum, 1986, pp. 3-27.

12. Parcel GS, Perry CL, Taylor WC: Beyond demonstration: Diffusion of health promotion innovations, in Bracht $\mathrm{N}$ (ed.): Health Promotion at the Community Level. Newbury Park, CA, Sage, 1990, pp. 229-252.

13. Clark N, Zimmerman BJ: A social cognitive view of self-regulated learning about health. Health Educ Res 5(3):371-379, 1990.

14. Freire P: Education for Critical Consciousness. New York, Seabury, 1973.

15. Stewart MJ: Social support: Diverse theoretical perspectives. Soc Sci Med 28(12):275-282, 1989.

16. Green LW, Kreuter MW: Health Promotion Planning: An Educational and Environmental Approach. Palo Alto, CA, Mayfield, 1991.

17. Simons-Morton DC, Simons-Morton BG, Parcel GS, Bunker JF: Influencing personal and environmental conditions for community health: A multi-level intervention model. Fam Community Health 11:25-35, 1988.

18. McLeroy KR, Bibeau D, Steckler A, Glanz K: An ecological perspective on health promotion programs. Health Educ $Q$ 15:351-377, 1988.

19. Stokols D: Establishing and maintaining health environments: Towards a social ecology of health promotion. Am Psychol 47:6-22, 1992.

20. Hancock T: Health, human development and the community ecosystem: Three ecological models. Health Promotion Int 8:41-47, 1993.

21. Wallerstein N, Bernstein E: Community Empowerment, Participatory Education, and Health-Part I (Special issue). Health Educ Q 21(2), 1994.

22. Wallerstein N, Bernstein E: Community Empowerment, Participatory Education, and Health-Part II (Special issue). Health Educ Q 21(3), 1994.

23. Freudenberg N, Zimmerman M: The lessons of ADS prevention for public health practice, in Freudenberg N, Zimmerman M (eds.): AIDS Prevention in the Community: Lessons From the First Decade. Washington, DC, American Public Health Association, in press.

24. Janz NK, Becker MH, Hartman PE: Contingency contracting to enhance patient compliance: A review. J Patient Educ Counseling 5(4):165-178, 1984.

25. Becker MH, Maiman LA: Strategies for enhancing patient compliance. J Community Health 6:113-135, 1980.

26. Clark NM, Evans D, Zimmerman BJ, Levison MJ, Mellins RB: Patient and family management of asthma: Theory based techniques for the clinician. J Asthma 3(16):427-435, 1994.

27. Israel BA, Schuman SJ: Social support, control and the stress process, in Glanz K, Lewis FM, Rimer BK (eds.): Health Behavior and Health Education. San Francisco, CA, Jossey-Bass, 1990.

28. Daltroy LH, Morlino CI, Liang MH: Preoperative education for total hip and knee replacement patients. Arthritis Care Res 2:S8-S15, 1989.

29. Morisky DE, Malotte CK, Choi P, Davidson P, Rigler S, Sugland B, Langer M: A patient education program to improve adherence rates with antituberculosis drug regimens. Health Educ $Q$ 17:253-267, 1990.

30. Bartholomew LK, Parcel GS, Seiheimer DK, Czyzewski D, Spinelli SH, Congdon B: Development of a health education program to promote the self-management of cystic fibrosis. Health Educ $Q$ 18:415-443, 1991.

31. Strecher VJ: Improving physician-patient interactions: A review. Patient Counseling Health Educ 4:129-136, 1982.

32. Clark NM, Feldman CH, Evans D, Levison MJ, Wasilewski Y, Mellins RB: The impact of health education on frequency and cost of health care used by low income children with asthma. J Allergy Clin Immunol 78:108-115, 1986. 
33. Lorig K, Lubeck D, Kraines RG, Seleznick M, Holman HR: Outcomes of self-help education for patients with arthritis. Arthritis Rheum 28:680-685, 1985.

34. Winett R, King AC, Altman DG: Health Psychology and Public Health: An Integrative Perspective. New York, Pergamon, 1989.

35. Mittelmark MB, Hunt MK, Heath GW, Schmid TL: Realistic outcomes: Lessons from community-based research and demonstration programs for the prevention of cardiovascular diseases. J Public Health Policy 14:437-462, 1993.

36. Pierce JP, Evans N, Farkas A, Cavin SW, Berry C: Tobacco Use in California: An Evaluation of the Tobacco Control Program 1989-1993. La Jolla, CA, University of Califomia, San Diego, 1994.

37. Lorig K, Konkol L, Gonzalez V: Arthritis patient education: A review of the literature. Patient Educ Counseling 10:207-252, 1987.

38. Mullen PD, Laville EA, Biddle AK, Lorig K: Efficacy of psycho-educational interventions on pain, depression, and disability with arthritic adults: A meta-analysis. J Rheum 14(suppl. 15):33-39, 1987.

39. Kovar PA, Allegrante JP, MacKenzie CR, Peterson MGE, Gutin B, Charlson ME: Supervised fitness walking in patients with osteoarthritis of the knee: A randomized, controlled trial. Ann Intern Med 116:529-534, 1992.

40. Gottlieb BH: Social networks and social support: An overview of research practice, and policy implications. Health Educ Q 12:5-22, 1985.

41. Eng E, Young R: Lay health advisors as community change agents. Fam Community Health 15:24-40, 1992.

42. Watkins EL, Harlan C, Eng E, Gansky SA, Gehan D, Larson K: Assessing the effectiveness of lay health advisors with migrant farmworkers. Fam Community Health 16:72-87, 1994.

43. Flynn BC: Healthy cities: A model of community change. Fam Community Health 15:13-23, 1992.

44. Rivo M, Gray K, Whitaker M, Coward R, Biburd L, Timoll M, Curry C, Tuckson R: Implementing PATCH in public housing communities: The District of Columbia experience. $J$ Health Educ 23:148-152, 1992.

45. Overbo B, Ryan M, Jackson K, Hutchinson K: The homeless prenatal program: A model for empowering homeless pregnant women. Health Educ Q 21:187-198, 1994.

46. Wang C, Burris MA: Empowerment through Photo Novella: Portraits of participation. Health Educ $Q 21: 171-186,1994$.

47. Wallerstein N, Bernstein E: Empowerment education: Friere's ideas adapted to health education. Health Educ Q 15:379-394, 1988.

48. Department of Labor: Protecting People at Work: A Reader in Occupational Safety and Health. Washington, DC, U.S. Government Printing Office, 1980.

49. Freudenberg N: Not in Our Backyards! Community Action for Health and the Environment. New York, Monthly Review Press, 1984.

50. Bierer MF, Rigotti NA: Public policy for the control of tobacco-related disease. Med Clin North Am 76:515-539, 1992.

51. Rice RE, Atkin CK (eds.): Public Communication Campaigns (2nd ed.). Newbury Park, CA, Sage, 1990.

52. Wallack L: Mass communication and health promotion, in Rice RE, Atkin CE (eds.): Public Communication Campaigns (2nd ed.). Newbury Park, CA, Sage, 1990.

53. Montgomery K: The Harvard Alcohol Project: Promoting the designated driver on television, in Backer TE, Rogers EM (eds.): Organizational Aspects of Health Communication Campaigns: What Works. Newbury Park, CA, Sage, 1993.

54. Farquhar JW, Maccoby N, Wood P, Alexander JK, Breitrose H, Brown RW, Haskell WL, McAlister AL, Meyer AJ, Nash JD, Stern MP: Community education for cardiovascular health. Lancet 1:1192-1195, 1977. 
55. Luepker RV, Murray DM, Jacobs DR, Mittelmark MB, Bracht N, Carlaw R, Crow R, Elmer P, Finnegan J, Folsom AR, Grimm R, Hannan PJ, Jeffrey R, Lando H, McGovern P, Mullis R, Perry CL, Pechacek T, Pirie P, Sprafka JM, Weisbrod R, Blackburn H: Community education for cardiovascular disease prevention: Risk factor changes in the Minnesota Heart Health Program. Am J Public Health 84(9):1383-1393, 1994.

56. Christenson GM, Gold RS, Katz M, Kreuter MW: Results of the School Health Education Evaluation. J Sch Health 55(8):295-355, 1985.

57. Ross J, Nelson G, Kolbe L: Teenage health teaching modules evaluation. J Sch Health 61(1):19-42, 1991.

58. Walter $\mathrm{H}$, Wynder E: The development, implementation, evaluation, and future directions of chronic disease prevention programs for children: The "Know Your Body" studies. Prev Med 18(1):59-71, 1989.

59. Kirby D, Short L, Collins J, Rugg D, Kolbe L, Howard M, Miller B, Sonenstein F, Zabin LS: School-based programs to reduce sexual risk behaviors: A review of effectiveness. Public Health Rep 109(3):339-360, 1994.

60. Evans D, Clark NM, Feldman CH: School health education programs for asthma. Clin Rev Allergy 5:207-212, 1987.

61. Pelletier KR: A review and analysis of the health and cost-effective outcome studies of comprehensive health promotion and disease prevention programs at the worksite. Am J Health Promotion 7:50-62, 1993.

62. Glasgow RE, McCaul KD, Fisher KJ: Participation in worksite heal th promotion: A critique of the literature and recommendations for future practice. Health Educ Q 20:391-408, 1993.

63. Wigal JK, Creer TL, Kotses H, Lewis P: A critique of 19 self-management programs of childhood asthma: Part II. Development and evaluation of the programs. Pediatr Asthma Allergy Immunol 4:17-39, 1990.

64. Lorig K, Konkol L, Gonzales V: Arthritis patient education: A review of the literature. Patient Educ Couns 10:207-252, 1987.

65. Mullen PD, Mains DA, Velez R: A meta-analysis of controlled trials of cardiac patient education. Patient Educ Counseling 19:143-162, 1992.

66. Padgett D, Mumford E, Hynes M, Carter R: Meta-analysis of the effects of educational and psychosocial interventions on management of diabetes mellitus. $J$ Clin Epidemiol 41(10):1007-1030, 1988.

67. Jones LC: A meta-analytic study of the effects of childbirth education on the parent-infant relationship. Health Care Women Int 7:357-370, 1986.

68. Strecher VJ, Kreuter MW, Den Boer DJ, Kobrin S, Hospers HJ, Skinner CS: The effects of computer-tailored smoking cessation messages in family practice settings. $J$ Fam Pract 39(3):262-270, 1994.

69. Skinner CS, Strecher VJ, Hosper H: Physician recommendations for mammography: Do tailored messages make a difference? Am J Public Health 84(1):43-49, 1993.

70. Hollis JF, Lichtenstein E, Vogt TM, Stevens VJ, Biglan A: Nurse assisted counseling for smokers in primary care. Ann Intern Med 118(7):521-525, 1993.

71. Inui TS, Yourtee EL, Williamson JW: Improved outcomes in hypertension after physician tutorials. Ann Intern Med 84:646-651, 1976.

72. Stone EJ, McGraw SA, Osganian SK, Elder JP (eds.): Process evaluation in the multicenter Child and Adolescent Trial for Cardiovascular Health (CATCH) (Special issue). Health Educ $Q$ Suppl. 2:S1-S148, 1994.

73. Gottlieb NH, Wright D, Sneden GG: Using PRECEDE/PROCEDE for Implementation Planning: Infusion of the Texas "Top Priority" Worksite Health Promotion Program. Unpublished manuscript, University of Texas at Austin, 1994.

74. Perez-Stable EJ, VanOss Marin B, Marin G: A comprehensive smoking cessation program for the San Francisco Bay Area Latino community: Programa Latino Para Dejar de Fumar. Amer $J$ Health Promotion 7(6):430-442, 475, 1993. 
75. Rogers E: Diffusion of Innovations. New York, Free Press, 1993.

76. Uba L: Cultural barriers to health care for Southeast Asian refugees. Public Health Rep 107:544-548, 1992.

77. Gielen AC, Faden RR, O'Campo E et al: Women's protective sexual behaviors: A test of the health belief model. AIDS Educ Prev 6(1):1-11, 1994.

78. Rosser SV: Perspectives: AIDS and women. AIDS Educ Prev 3(3):230-240, 1991.

79. Marin G, VanOss Marin B, Otero-Sabogal R, Sabogal F, Perez-Stable EJ: The role of acculturation on the attitude, norms and expectations of Hispanic smokers. J Cross-Cultural Psychol 20:399-415, 1989.

80. Marin G, Posner SF, Kinyon JB: Alcohol expectancies among Hispanics and non Hispanic Whites: Roles of drinking status and acculturation. Hispanic J Behav Sci 15:373-381, 1993.

81. Clark NM, Levison MJ, Evans D, Wasilewski Y, Feldman CH, Mellins RB: Communication within low income families and the management of asthma. Patient Educ Counseling 15:191-210, 1990.

82. Whelton PK, Perneger TV, Klag MJ, Brancati FL: Epidemiology and prevention of blood pressure-related renal disease. J Hypertens 10(suppl. 7):S77-S84, 1992.

83. Cohen RA, VanNostrand JF, Fumer SE (eds.): Chartbook on health data on older Americans: United States, 1992. Vital Health Stat 3(29), 1993.

84. Lorig K, Gonzalez V: The integration of theory with practice: A 12-year case study. Health Educ $Q$ 19:355-368, 1992.

85. Connell CM, Fisher EB Jr, Houston CA: Relationship among social support, diabetes outcomes, and morale for older men and women. JAging Health 4:77-100, 1992.

86. Burhansstipanov L, Dresser CM: Documentation of the Cancer Research Needs of American Indians and Alaska Natives (Native American Monograph No. 1). Bethesda, MD, National Cancer Institute, 1993. (NIH Pub. No. 93-3603.)

87. Stillman FA, Bone LR, Rand C, Levine DM, Becker DM: Heart, body, and soul: A churchbased smoking-cessation program for urban African Americans. Prev Med 22(3):335-349, 1993.

88. Eng E: The Save Our Sisters Program: A social network strategy for reaching rural Black women. Cancer 72(3):1071-1077, 1993.

89. Eng E, Parker E: Measuring community competence in the Mississippi delta: The interface between program evaluation and empowerment. Health Educ Q 21:199-220, 1994.

90. Cook TD, Campbell DT: Quasi-Experimentation: Design and Analysis for Field Settings. Boston, Houghton Mifflin, 1979.

91. Michielutte R, Dignan MB, Wells HB, Young LD, Jackson DS, Sharp PC: Development of a community cancer education program: The Forsyth County, NC cervical cancer prevention project. Public Health Rep 104:542-551, 1989.

92. COMMIT Research Group: Community Intervention Trial for Smoking Cessation (COMMIT): Summary of design and intervention. J Natl Cancer Inst 83:1620-1628, 1991.

93. Dignan M, Michielutte R, Sharp P, Young L, Daniels L: Use of process evaluation to guide Forsyth County's project to prevent cervical cancer. Public Health Rep 106:73-77, 1991.

94. Hanson WB, Graham JW: Preventing alcohol, marijuana, and cigarette use among adolescents: Peer pressure resistance training versus establishing conservative norms. Prev Med 20:414-430, 1991.

95. Clark NM, Janz NK, Becker MH, Schork MA, Wheeler J, Liang J, Dodge JA, Keteyian S, Rhoads KL, Santinga JT: Impact of self-management education on the functional health status of older adults with heart disease. The Gerontologist 32:438-443, 1992.

96. Clark NM, Janz NK, Dodge JA. Garrity CR: Managing heart disease: A study of the experience of older women. J Am Med Wom Assoc 49:202-206, 1994.

97. Mullen PD, McCuan RA, Iverson DC: Evaluation of health education and promotion programs: A review of qualitative approaches. Adv Health Educ Promotion 1:467-498, 1986.

98. Basch CE: Focus group interview: An underutilized research technique for improving theory and practice in health education. Health Educ Q 14:411-448, 1987. 
99. Israel BA, Checkoway B, Schulz A, Zimmerman MA: Health education and community empowerment: Conceptualizing and measuring perceptions of individual, organizational, and community control. Health Educ Q 21:149-170, 1994.

100. Steckler A: The use of qualitative evaluation methods to test internal validity. Evaluation Health Professions 12:115-133, 1989.

101. Heaney CA: Strengths and Challenges in the Evaluation of Health Education Interventions. Paper prepared for the CDC/SOPHE conference Creating Capacity: Research Agenda for Health Education, September, 1994.

102. McGraw SA, Stone EJ, Osganian SK, Elder JP, Perry CL, Johnson CC, Parcel GS, Webber LS, Luepker RV: Design of process evaluation within the Child and Adolescent Trial for Cardiovascular Health (CATCH). Health Educ Q 15:351-375, 1988.

103. Corbett K, Thompson B, White N, Taylor M: Process evaluation in the community intervention for smoking cessation (COMMTT). Int Q Community Health Educ 11(3):291-309, 1990-1991.

104. Mullen PD: The (already) activated patient: An alternative to mediococentrism. Springer Service Health Care Society 4:281-298, 1980.

105. Garrity TF, Garrity AR: The nature and efficacy of intervention studies in the National High Blood Pressure Education Research Program. Hypertension 3(1):591-595, 1985.

106. Green LW: Toward cost-benefit evaluations of health education: Some concepts, methods, and examples. Health Educ Monographs 2(suppl. 1):34-64, 1974. 